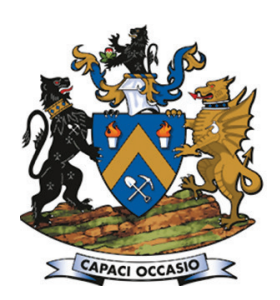

Affiliation:

Department of Materials Science \& Engineering, Carnegie Mellon University, Pittsburgh, PA, U.S.A.

Correspondence to:

P.C. Pistorius

Email:

pistorius@cmu.edu

Dates:

Received: 1 Nov. 2018

Revised: 26 Apr. 2019

Accepted: 26 Apr. 2019

Published: June 2019

\section{How to cite:}

Pistorius, P.C.

Slag carry-over and the production of clean steel. The Southern African Insitute of Mining and Metallurgy

DOI ID:

http://dx.doi.org/10.17159/24119717/KN01/2019

ORCID ID:

P.C. Pistorius

https://orcid.org/0000-0002-

2966-1879

This paper was first presented at the Furnace Tapping 2018

Conference, 15-16 October

2018, Nombolo Mdhluli

Conference Centre, Kruger

National Park, South Africa.

\title{
Slag carry-over and the production of clean steel
}

\section{P.C. Pistorius}

\section{Synopsis}

For effective steel refining in the ladle (secondary steelmaking) the amount of steelmaking slag that is transferred from primary steelmaking must be limited, because the steelmaking slag contains iron oxide, manganese oxide, and phosphorus oxide. Adverse effects of slag carry-over include increased consumption of deoxidizers, phosphorus pick-up by the steel, and increased ladle refractory wear. Infrared imaging at longer wavelengths is an effective non-contact method to detect slag in the tapping stream. Various devices are used to shut off the tapping stream rapidly. These include slag darts, pneumatic slag stoppers, and slide gates for steelmaking converters, and eccentric bottom tapping for electric arc furnaces.

\section{Keywords}

steelmaking, phosphorus, slag carry-over.

\section{Introduction}

Oxygen converters and electric arc furnaces are used for primary steelmaking. For both process types, the product (liquid crude steel) has a similar composition: largely liquid iron, with around 800-1000 parts per million (ppm, by mass) dissolved oxygen and low but significant concentrations of carbon, nitrogen, and phosphorus. The steel is tapped into a ladle, which serves as the refining vessel to adjust the final steel composition and temperature before casting.

Some steelmaking slag is inevitably tapped with the liquid steel. The mass of steelmaking slag tapped with the steel is termed 'slag carry-over'. Controlling and limiting slag carry-over from steelmaking is a primary requirement for clean steel production (Fandrich, Lüngen, and Wuppermann, 2008). Steel cleanliness refers to limiting the concentrations of dissolved impurities (such as nitrogen, oxygen, phosphorus, and sulphur) and of nonmetallic inclusions (oxides, sulphides, and nitrides) in liquid steel and in the final solid steel product. Of these, the strongest effect of slag carry-over is on the content of dissolved phosphorus in the liquid steel.

Slag carry-over increases the amount of deoxidant needed, increases wear of ladle refractory, and causes reversion of phosphorus (transfer of phosphorus from slag back to the steel). This paper briefly reviews the fundamental origin of these effects, and summarizes the practical methods that are used to limit slag carry-over.

\section{Steelmaking process conditions}

In primary steelmaking, conditions are relatively oxidizing because of oxygen injection. In steelmaking converters, oxygen is injected to react with the carbon in the hot metal (containing some $4 \%$ carbon) to convert this into crude steel with around $0.1 \%$ carbon. The total oxygen consumption in steelmaking converters is $50-70 \mathrm{Nm}^{3}$ per ton steel (Remus et al., 2013). In electric arc furnaces (EAFs), oxygen is used to lance molten scrap, and oxygen also reacts with carbon (from injected carbon and carbonbearing raw materials such as pig iron). Combustion of carbon provides energy and produces carbon monoxide to foam the furnace slag. The median oxygen consumption in electric arc furnaces in the USA is approximately $35 \mathrm{Nm}^{3} / \mathrm{t}$ (Association for Iron \& Steel Technology, 2018b). For both converters and EAFs the resulting oxygen activity in steel, expressed as the partial pressure of $\mathrm{O}_{2}$, is around $10^{-9}$ atm. The relatively oxidizing conditions result in a high concentration of $\mathrm{FeO}$ in the steelmaking slag (typically around $25 \% \mathrm{FeO}$, with some $\mathrm{MnO}$ present too). Oxidizing conditions and a high slag basicity are necessary to dephosphorize the steel (Turkdogan, 1996). Phosphorus, which originates from the 


\section{Slag carry-over and the production of clean steel}

steelmaking raw materials, must be removed to achieve the required mechanical properties of steel. A typical specification is that the phosphorus concentration in steel should not exceed 150 ppm by mass. Phosphorus is removed from steel by oxidation, converting neutral phosphorus atoms to phosphate ions that dissolve in the slag. Primary steelmaking is the only step in steel production that allows for dephosphorization, and phosphorus removal is an important requirement in optimization of primary steelmaking practices (Wünnenberg and Cappel, 2008).

The extent of dephosphorization can be expressed as the ratio of the mass percentage of phosphorus in the slag to that in the steel:

$$
L_{\mathrm{P}}=\frac{(\% \mathrm{P})_{\text {slag }}}{[\% \mathrm{P}]_{\text {steel }}}
$$

This ratio $L_{P}$, the phosphorus partitioning coefficient, depends on the temperature, slag composition, and reaction kinetics; typical values are in the range of 50-100 for primary steelmaking. For $L_{P}=50$, every $20 \mathrm{~kg}$ of slag contains as much phosphorus as $1 \mathrm{t}$ of steel. The much higher concentration of phosphorus in steelmaking slag than in steel is one of the main reasons why it is important to limit slag carry-over.

After tapping into a ladle, the steel is deoxidized by adding elements with a strong affinity for oxygen (such as aluminium, silicon, or silicon and manganese). Oxygen must be removed to avoid the loss of (subsequently added) alloying elements by oxidation, and to avoid carbon monoxide porosity during solidification. Deoxidation lowers the concentration of dissolved oxygen from around $800 \mathrm{ppm}$ to just a few ppm (in the case of aluminium-killed steel). The much lower dissolved oxygen concentration is reflected in an $\mathrm{O}_{2}$ activity of around 10-15 atm., some six orders of magnitude smaller than in primary steelmaking.

The much more reducing conditions in the ladle (secondary steelmaking conditions) cause a large shift in redox reactions. At equilibrium, the concentrations of iron oxide and phosphate in the ladle slag are near zero: all the $\mathrm{FeO}, \mathrm{MnO}$, and $\mathrm{P}_{2} \mathrm{O}_{5}$ in carry-over furnace slag would be reduced by deoxidation and returned to the steel. The typical concentration of silica $\left(\mathrm{SiO}_{2}\right)$ in steelmaking slag is 15-20\% (Remus et al., 2013). Silica from carry-over slag is partially reduced by aluminium in deoxidized steel, causing some silicon pick-up by the steel.

\section{Effects of slag carry-over}

A survey of steel plants that was published more than two decades ago (Block and Piotrowiak, 1996) remains a useful summary of the main reasons to limit slag carry-over. For both electric arc furnace and oxygen converter plants, the main reported advantages of lower slag carry-over are improved oxide cleanliness of steel, less consumption of deoxidizer, decreased reversion of phosphorus (or of silicon), and improved ladle refractory life.

'Oxide cleanliness' refers to the concentration of inclusions in the liquid steel. The basis of the effect of slag carry-over on oxide cleanliness is that $\mathrm{FeO}$ and $\mathrm{MnO}$ in the slag are sources of oxygen, and continue to react with dissolved aluminium (or other deoxidizers) in the steel to form alumina (or other oxide) inclusions until the concentrations of $\mathrm{FeO}$ and $\mathrm{MnO}$ are near zero. Such sustained formation of fresh oxide inclusions tends to increase the total inclusion concentration in the steel: a correlation was reported between the inclusion concentration and the sum $(\% \mathrm{FeO}+\% \mathrm{MnO})$ in ladle slag at the end of ladle treatment (Schwerdtfeger, 1983). Low inclusion concentrations were associated with (\%FeO $+\% \mathrm{MnO})$ less than approximately $4 \%$. However, there are subtleties to the effect of $(\mathrm{FeO}+\mathrm{MnO})$ on oxide inclusion composition: the less-reducing condition imparted by retaining a few per cent of $\mathrm{FeO}$ and $\mathrm{MnO}$ in the ladle slag serves to retard transfer of dissolved magnesium to the steel, and so delays formation of magnesium spinel inclusions (approximate composition $\mathrm{MgAl}_{2} \mathrm{O}_{4}$ ) (Ahlborg, 2001; Kumar, Ahlborg, and Pistorius, 2017). Spinels are associated with clogging of continuous caster nozzles, so delaying formation of spinels during ladle treatment (by retaining some $\mathrm{FeO}$ and $\mathrm{MnO}$ in the ladle slag) can be beneficial for some steel grades.

Deoxidizer consumption and phosphorus reversion are strongly affected by slag carry-over, and this can be readily seen from a simple mass balance. The calculation was based on steel that contains 800 ppm dissolved oxygen upon tapping, with the steelmaking slag containing $0.25 \% \mathrm{P}$ and a total of $25 \% \mathrm{FeO}$ plus $\mathrm{MnO}$. The steel was assumed to be deoxidized with aluminium after tapping into the ladle, with $0.05 \% \mathrm{Al}$ remaining in solution in the steel after deoxidizing. The amount of deoxidizer ( $\mathrm{Al})$ required is the sum of the $\mathrm{Al}$ that goes into solution $(0.05 \%$, or $0.5 \mathrm{~kg} \mathrm{Al}$ per ton of steel) and the $\mathrm{Al}$ required to reduce dissolved oxygen (from the steel) and $\mathrm{FeO}+\mathrm{MnO}$ (from the slag) according to the following reactions:

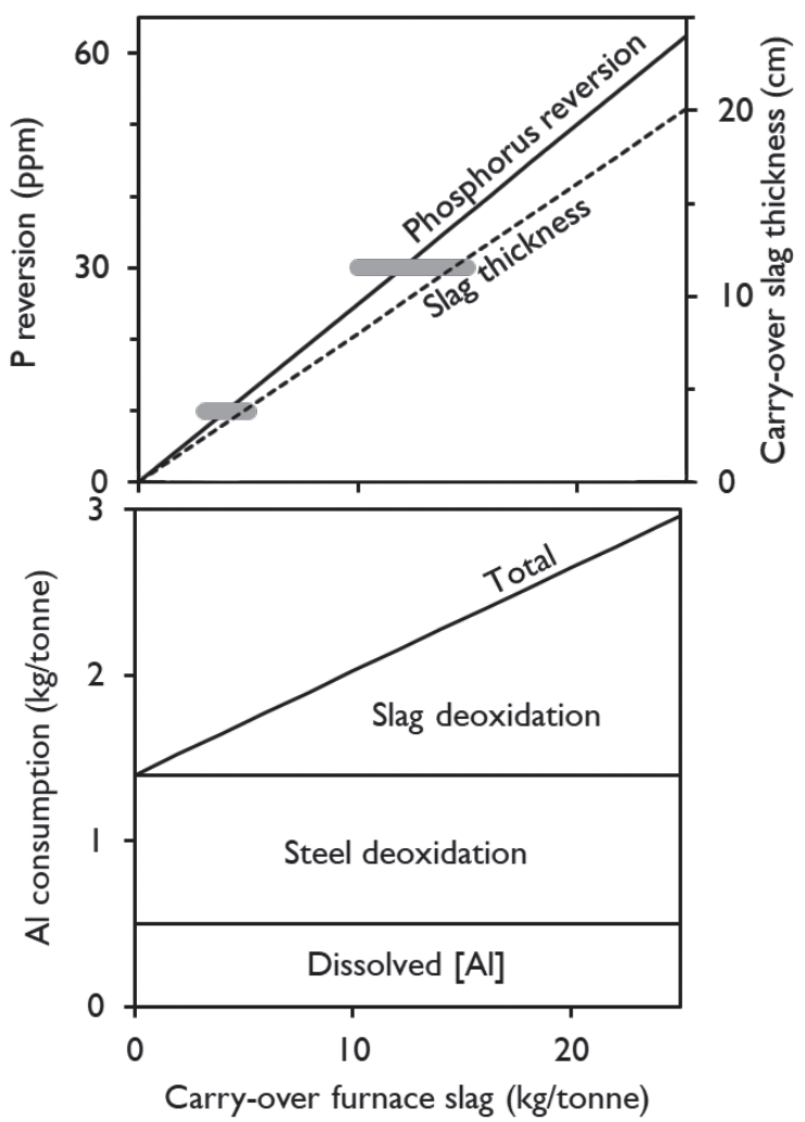

Figure 1-Calculated effect of carry-over of steelmaking slag on consumption of aluminium (deoxidizer; lower graph), and on phosphorus reversion to the steel (upper graph; horizontal grey bars give the phosphorus reversion values reported by Di Napoli Guzela et al., 2003). The estimated thickness of the layer of carry-over slag is also shown in the upper graph 


$$
\begin{aligned}
& 2 \mathrm{Al}+3 \mathrm{O} \rightarrow \mathrm{Al}_{2} \mathrm{O}_{3} \\
& 2 \mathrm{Al}+3 \mathrm{FeO} \rightarrow \mathrm{Al}_{2} \mathrm{O}_{3}+3 \mathrm{Fe} \\
& 2 \mathrm{Al}+3 \mathrm{MnO} \rightarrow \mathrm{Al}_{2} \mathrm{O}_{3}+3 \mathrm{Mn}
\end{aligned}
$$

Reduction of $\mathrm{SiO}_{2}$ and $\mathrm{P}_{2} \mathrm{O}_{5}$ is not considered in the aluminium reactions - while phosphorus reversion has a significant effect on steel composition, the effect of reduction of these two oxides on $\mathrm{Al}$ consumption is small compared with reactions $[2 \mathrm{a}]$ to $[2 \mathrm{c}]$.

The calculated relationship between slag carry-over and deoxidizer consumption is shown in Figure 1, illustrating that the effect is significant. The calculated extent of phosphorus reversion is also notable; phosphorus reversion results from all the phosphorus in the carry-over slag ( $0.25 \%$ of the slag mass) returning to the steel upon reduction (deoxidation). As Figure 1 illustrates, the calculated values for phosphorus reversion are consistent with the industrial observations of Di Napoli Guzela et al., (2003). They reported that without a slag stopper (described later), the amount of carry-over slag from oxygen converters is $10-15 \mathrm{~kg}$ per ton of steel, resulting in approximately $30 \mathrm{ppm}$ of phosphorus reversion; with a stopper, slag carry-over is reduced to $3-5 \mathrm{~kg} / \mathrm{t}$ and phosphorus reversion to some $10 \mathrm{ppm}$.

Figure 1 also shows the depth of the layer of carry-over slag on the steel in the ladle. This depth was calculated for a slag density of $2.9 \mathrm{t} / \mathrm{m}^{3}$ (Mills and Keene, 1987) and assuming that the ladle is approximately cylindrical, with the depth of the steel equal to the ladle diameter. As Figure 1 indicates, the depth of the layer of carry-over slag is significant (typically several centimetres); measurement of the thickness of this layer is one of the approaches used in steel plants to quantify slag carry-over. As described by Abraham and Chen (2011), the procedure is to dip a steel rod into the steel bath in the ladle after tapping: the rod melts off at the steel-slag interface and slag adheres to the length of the rod within the slag; this length is readily measured.

The adverse effect of slag carry-over on the wear of ladle refractory is generally ascribed to the presence of $\mathrm{MnO}$ in the steelmaking slag. Experimental studies have shown that increased manganese oxide concentrations increase the wear rate of MgO-carbon refractory, which is typically used for the ladle slag line (Ikesue et al., 1988; Um et al., 2012). The corrosive effect of MnO appears to be linked to both oxidation of carbon by $\mathrm{MnO}$ (causing loss of carbon from the refractory) and the rapid mass transfer of MnO in the slag (Lee et al., 2001).

\section{Limiting slag carry-over}

Slag carry-over is limited by detecting slag in the tap stream, and then interrupting the flow of steel and slag. In EAFs, an additional approach is to retain a significant 'hot heel' of steel in the furnace to serve as a barrier to slag flow. Each of these approaches is briefly described here.

An alternative approach is to remove slag from the steel in the ladle after tapping, by raking off the slag. This is a less common approach (Block and Piotrowiak, 1996), and complete slag removal is difficult to achieve (Steneholm et al., 2018).

\section{Slag detection}

Surveys of steel plants 20-25 years ago indicated that most plants relied on visual detection of slag in the tapping stream (da Silva, Bergman, and Lindfors, 1993; Block and Piotrowiak,

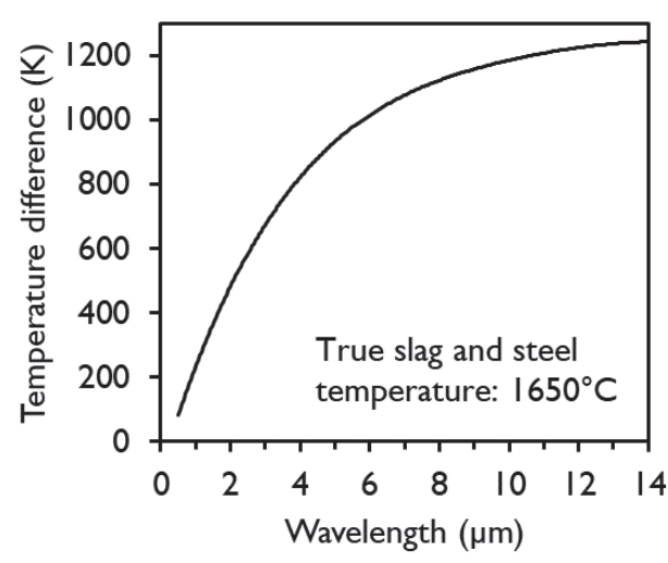

Figure 2-Difference in spectral radiance temperature between slag and steel, for different wavelengths. Calculated for steel and slag at $1650^{\circ} \mathrm{C}$. The difference is much larger in the mid-infrared $(>8 \mu \mathrm{m})$ than in the visible range (around $0.5 \mu \mathrm{m}$ ). Adapted from Peacock (2000)

1996). At that time, the only alternative was electromagnetic detection of the slag - requiring a detector at the tap-hole, with associated maintenance concerns (Boyle et al., 2001). The electromagnetic slag detection system uses two coils around the tap stream. Alternating current applied to one coil induces an electromagnetic field that is detected by the other coil; the difference in electromagnetic properties of steel and slag (within the coils) affects the field and the difference is used to detect the presence of slag in the tap stream (Sahai and Emi, 2008; AMEPA, 2018).

In contrast to the small number of plants that used a method other than visual detection of slag 20-25 years ago, some $84 \%$ of the plants listed in the latest AIST Basic Oxygen Furnace Roundup (Association for Iron and Steel Technology, 2018a) use a slag detection method (the plants surveyed are worldwide, but do not include China, Japan, Russia, South Korea, or continental Europe).

It appears that the development that made reliable nonvisual slag detection possible is infrared detection of slag in the tap stream. The infrared measurement relies on the difference in emissivity between steel and slag; this difference is much larger in the mid-infrared range (several $\mu \mathrm{m}$ wavelength) than in the visible range (Peacock, 2000). One way to express this difference is with the spectral radiance temperature, which is the temperature of a black body that would give the same radiance as slag or steel, at a particular wavelength. Slag has higher emissivity than steel, and so appears brighter. Figure 2 demonstrates that the resulting difference in spectral radiance temperature is much larger at longer wavelengths; the difference remains large even with significant attenuation (absorption of light by fumes) (Peacock, 2000). This means that the infrared camera can be placed at a safe distance from the tapping stream, and can provide a reliable non-contact indication as soon as slag is detected (Viale et al., 2007). Such detection systems are available from several equipment suppliers (Luk'yanov et al., 2017).

\section{Slag stopping}

To limit slag carry-over, it is necessary to stop the flow soon after slag is detected: A typical tapping rate of a large steelmaking 


\section{Slag carry-over and the production of clean steel}
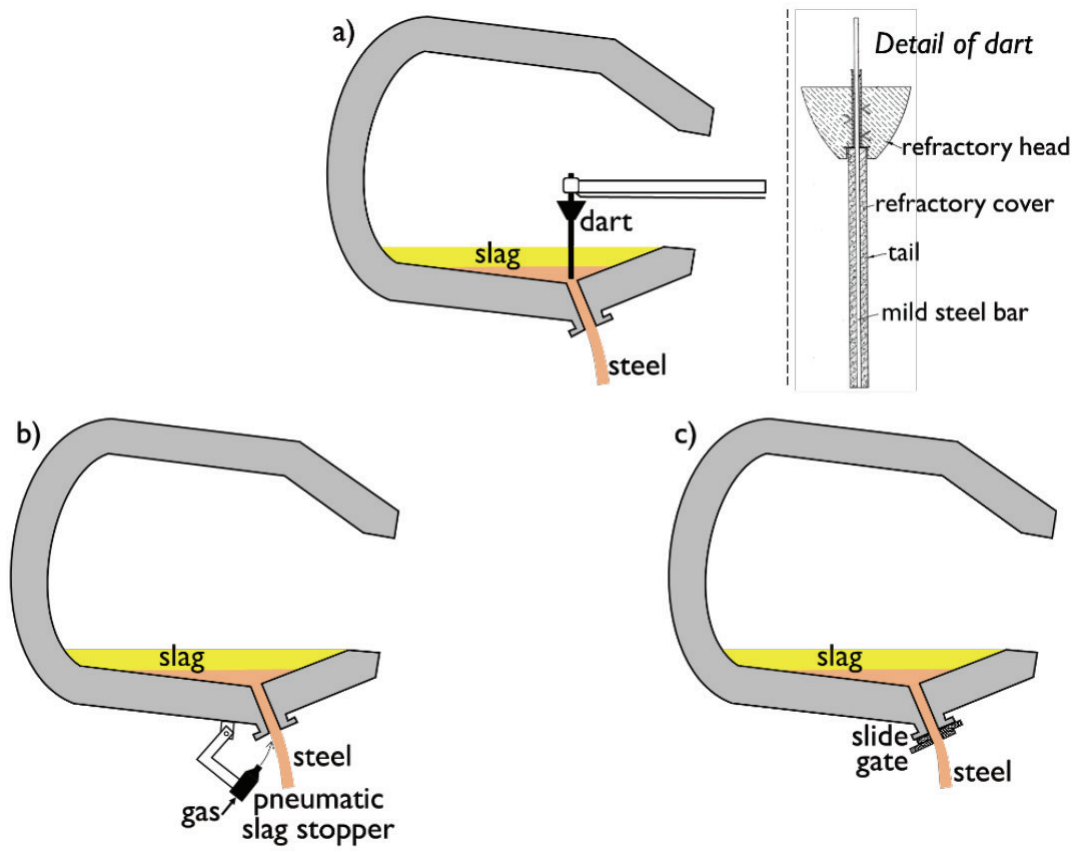

Figure 3-Illustration of methods to stop slag flow from an oxygen converter: (a) slag dart; (b) pneumatic slag stopper; (c) slide gate. Adapted from Orehoski and Gray (1986), Eastwood (1995), Wiesel (2003), and Maanshan Yushan Metallurgy New Materials

converter is around 1.2 t/s (Luk'yanov et al., 2017), emphasizing the need for rapid interruption of the flow as soon as slag is detected. During tapping of steelmaking converters and EAFs, the vessel is tilted to pour out the steel. One approach is to tilt back the furnace when slag is detected, but this is too slow to limit slag carry-over to low levels; for steelmaking converters, typical carry-over in such cases is $10-15 \mathrm{~kg} / \mathrm{t}$ (Di Napoli Guzela et al., 2003).

\section{Slag stopping: steelmaking converters}

Figure 3 illustrates methods commonly used to stop slag flow from steelmaking converters. The dart (Figure $3 \mathrm{a}$ ) has an overall density that is between that of the slag and the steel. When it is dropped into the tap-hole, it limits slag flow through the taphole and counteracts vortex formation; if allowed to form, the vortex would draw slag through the tap-hole before all the steel has been drained. Figure $3 \mathrm{~b}$ shows a pneumatic slag stopper; this swings into place (by the action of a pneumatic cylinder) and stops the flow by blowing gas into the tap-hole at a high supply pressure, of around 10 bar (Boyle et al., 2001). A slide gate (Figure $3 \mathrm{c}$ ) uses sliding refractory components, each with a hole for tapping: when the holes in the components are aligned, steel can flow; when slag is detected, the components are moved to take the holes out of alignment and so stop the flow (Lewis 1885). Wiesel (2003) described the development of slide gates for converters, including approaches to limit the effects of mechanical and thermal shock on the refractory material. An advantage of slide gates is the high rate of closure. Slide gates are now available for a wide range of converter sizes (Maanshan Yushan Metallurgy New Materials, 2018).

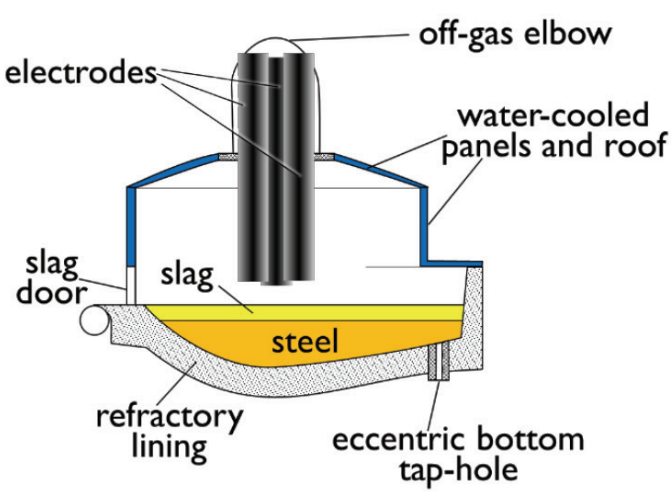

Figure 4-Schematic cross-section of an electric arc furnace, showing an eccentric bottom tap-hole

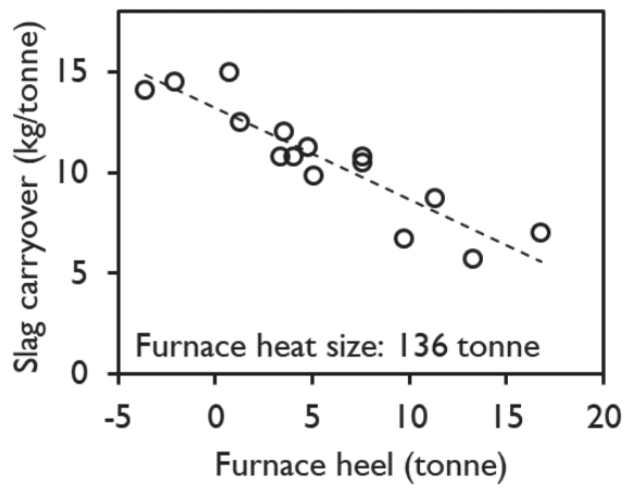

Figure 5-Relationship between the amount of steel retained as a hot heel and slag carry-over from an electric arc furnace. Adapted from Abraham and Chen (2011) 


\section{Slag carry-over and the production of clean steel}

\section{Slag stopping: electric arc furnaces}

Most modern EAFs use eccentric bottom tapping (EBT): a tap-hole at the bottom of the furnace (offset from the centre of the furnace) is used to drain out the steel (Jones, Bowman, and Lefrank, 1998); see Figure 4. The tap-hole is closed with a 'flapper' or a slide gate. The reported lifetime of an eccentric bottom tap-hole is $150-180$ heats (Heinen, 1997). Some furnaces have spouts to tap steel from the side of the furnace. A siphon spout uses a submerged entry to allow separation of steel and slag; the reported life is some 300 heats (Heinen, 1997). A slide gate can also be added to the spout to allow rapid shut-off of tapping (Jones, Bowman, and Lefrank, 1998; Heinen, 1997).

In the case of eccentric bottom tapping, retaining some steel in the furnace is essential to avoid slag carry-over by vortex formation. The retained steel is termed a 'hot heel'. The volume of the hot heel has a strong effect on slag carry-over; Figure 5 illustrates that a hot heel of some $10 \%$ of the tap mass was sufficient to decrease slag carry-over to around $7 \mathrm{~kg} / \mathrm{t}$. In Figure 5, a negative hot heel implies that there was no steel left in the furnace and the tap steel stream consisted entirely of slag at the end of tap (S. Abraham, personal communication).

\section{Conclusions}

Slag-free tapping is the starting point for production of clean steel. Slag carry-over of a few kilogram of slag per ton of steel is achievable with the current technological solutions: a combination of slag detection, and a method to stop flow rapidly.

\section{Acknowledgements}

The support of the industrial members of the Center for Iron and Steelmaking Research at Carnegie Mellon University is gratefully acknowledged. I am also grateful for helpful comments by Mr Herman Moggee of RHI-Magnesita, and Dr Sunday Abraham of SSAB Americas.

\section{References}

Abraham, S. and Chen, S. 2011. Process for optimizing steel fabrication. US patent application 2011/0174457 A1.

AhlBorg, K. 2001. Seven ways to shut down the caster. Proceedings of the 84th Steelmaking Conference, Baltimore, MD, 25-28 March 2001. Iron \& Steel Society of AIME. pp. 861-869.

AmePA Process Measurement Systems. 2018. ESD - Electromagnetic slag detection. https://amepa.de/en/produkte/tsd-slag-detection/

Association for Iron \& Steel Technology. 2018a. AIST basic oxygen furnace roundup. Iron \& Steel Technology, vol. 15, no. 4. pp. 194-201.

Association for Iron \& Steel Technology. 2018b. AIST electric arc furnace roundup. Iron \& Steel Technology, vol. 15, no. 1. pp. 124-147.

Bцоск, F.-R., and Pıотвошіак, R. 1996. Verringerung der Menge an Mitlaufschacke bei der Stahlherstellung. Stahl und Eisen, vol.116. pp. 95-99.

Boyle, C.A., OlszewsKi, J.A., DiFiore, N., and DAum, T. 2001. Installation of pneumatic slag stoppers at U.S. Steel's Edgar Thomson Plant. AISE Steel Technology, May. pp. $39-40$

DA Silva, W.C., Bergman, D., and Lindfors, N.O. 1993. Slag carryover in oxygen converters: an international review. Steel Times International. pp. 91-95.

Di Napoli Guzela, D., de Oliveira, J.G., Staudinger, G., and Müller, J. 2003. The ultimate LD steelmaking converter. Steel Times International, April/May. pp 20-26.
EAstwood, O. 1995. Metallurgical dart and method of assembly. US patent 5,451,036.

FAndRich, R., Lüngen, H.B., and Wuppermann, C.-D. 2008. Actual review of secondary metallurgy. Revue de Métallurgy - CIT, vol. 105. pp. 364-374.

HeInEN, K.-H. 1997. Elektrostahlerzeugung, 4th edn. Verlag Stahleisen. Düsseldorf.

Ikesue, A., Yamamoto, H., Shikano, H., and Hiragushi, K. 1988. Corrosion mechanism of $\mathrm{MgO}-\mathrm{C}$ refractories by manganese oxide containing slag. Ceramic Transactions, vol. 4. Advances in Refractories Technology. Fisher, R.E. (ed). The American Ceramic Society, Inc., Westerville, OH. pp. 464-488.

Jones, J.A.T., Bowman, B., and Lefrank, P.A. 1998. Electric furnace steelmaking. The Making, Shaping and Treating of Steel. 11th edn. Steelmaking and Refining Volume Fruehan, R.J. (ed.). AISE Steel Foundation, Pittsburgh, PA. pp. 525-660.

KumAR, D., AhlBoRg, K.C., and Pistorius, P.C. 2017. Application of kinetic model for industrial scale ladle refining process. Proceedings of AISTech2017. pp. 2693-2706.

LeE, M., Sun, S., Wright, S., and Jahanshahi, S. 2001. Effects of transition metals on the kinetics of slag-refractory reactions. Metallurgical and Materials Transactions B, vol. 32. pp. 25-29.

LEwIS, D.D. 1885. Stopper for ladles. US patent $311,902$.

Luk’yanov, S.I., Suspitsyn, E.S., Pishnograev, R.S., and Krasilnikov, S.S. 2017. Survey of melt stream infrared radiation parameters at various stages of steel tapping from basic oxygen furnace. International Journal of Advanced Manufacturing Technology, vol. 88. pp. 595-602.

MaAnshan Yushan MetalluRgy New Materials. 2018. http://en.masysyjxcl.com

MilLs, K.C. and KeEnE, B.J. 1987. Physical properties of BOS slags. International Materials Reviews, vol. 32. pp. 1-120.

OREHoski, M.A. and GRAY, R.D. 1986. Ladle refining processes. Iron and Steel Engineer, vol 63, no. 1. pp. 40-52.

PEAcock, G.R. 2000. Thermal imaging of liquid steel and slag in a pouring stream. Thermosense XXII. Dinwiddie , R.B. and LeMieux, D.H. (eds). Proceedings of SPIE, vol. 4020. pp. 50-60.

Remus, R., Monsonet, M.A.A., Roudier, S., and SAncho, L.D. 2013. Best available techniques (BAT) reference document for iron and steel production. European Union, Luxembourg. http://eippcb.jrc.ec.europa.eu/reference/

SAHAI, Y., and Emi, T. 2008. Tundish Technology for Clean Steel Production. World Scientific Publishing, Hackensack, NJ.

SchWERDTFEger, K. 1983. Present state of oxygen control in aluminum deoxidized steel. Archiv für das Eisenhüttenwesen, vol. 54. pp. 87-98.

Steneholm, K., Andersson, N.A.I., Tilliander, A., and Jönsson, P.G. 2018. The role of process control on the steel cleanliness. Ironmaking \& Steelmaking, vol. 45. pp. 114-124.

TuRkDogan, E.T. 1996. Fundamentals of Steelmaking. The Institute of Materials, London.

Um, H., LeE, K., Chol, J., and Chung, Y. 2012. Corrosion behavior of MgO-C refractory in ferromanganese slags. ISIJ International, vol. 52. pp. 62-67.

Viale, M., Martin, O., Muratori, F., Bertezzolo, U., Perez, J., and Usart, J. 2007. Application of on-line infrared thermography in steel making industry. Thermosense XXIX. Knettel, K.M., Vavilov, V.P., and Miles, J.J. (eds . ProceedingS of SPIE, vol. 6541. pp. 65410H-1-11.

WIESEL, M. 2003. Refractories for flow control - new systems, new solutions. Refractories Engineering, March. pp. 2-8.

WÜNNENBERG K., and CAPPEL J. 2008. Cost-saving operation and optimization on metallurgical reactions in BOF practice. Iron \& Steel Technology, vol. 5, no. 11. pp. 66-73. 